\title{
Das Comissões de Solidariedade ao Primeiro Comando da Capital em São Paulo
}

Marcos César Alvarez, Fernando Salla e Camila Nunes Dias

Introdução

As prisões tornaram-se objeto de crescente interesse para as ciências sociais ao longo do século XX. Diversos aspectos ocuparam a reflexão acadêmica durante os anos de 1950, sobretudo a partir da literatura norte-americana, como, por exemplo, a configuração da prisão como um sistema social, os descompassos entre os objetivos dessa organização e os resultados alcançados, as relações de poder estabelecidas entre os presos e seus custodiadores, as dinâmicas sociais entre os presos, os efeitos do encarceramento sobre as relações familiares, as rupturas da ordem interna etc.

As mudanças nas políticas penais, desde meados da década de 1970, que provocaram em muitos países um intenso processo de encarceramento (cf. Christie, 1999; Garland, 2001; Wacquant, 2001), ampliaram consideravelmente os objetos de interesse e o volume da reflexão acadêmica sobre as prisões. A redefinição dos objetivos e finalidades da prisão no mundo contemporâneo, os efeitos da longa permanência de presos em regime de confinamento mais severo, as revoltas e rebeliōes e a privatização de prisões foram alguns dos novos temas debatidos. 
Uma questão central que tem atravessado muitos dos eixos de reflexão sobre as prisóes é a do ajustamento dos indivíduos presos aos dispositivos disciplinares, bem como a da resistência a esses dispositivos através de estratégias complexas que mobilizam as ações individuais ou por meio da ação coletiva oriunda de grupos organizados que possam potencializar a não aceitação das regras impostas institucionalmente.

O foco da análise aqui empreendida são justamente os efeitos para a dinâmica prisional, e mesmo para a sociedade mais abrangente, da existência de grupos de presos não só constituídos e reconhecidos pelas autoridades como legítimos interlocutores na condução dos assuntos prisionais, mas também aqueles que buscam legitimidade entre os presos com base em outros fundamentos (códigos e lógicas do mundo do crime) que não o reconhecimento da legitimidade pela autoridade institucional. Trata-se de analisar essa dinâmica na sua verticalidade, ou seja, na relação dos custodiadores com os presos e vice-versa, e na dimensão de sua horizontalidade, isto é, entre os próprios presos. Em ambas as direçōes, são muitos os efeitos dessas relaçôes no interior das prisóes e para além de seus muros.

Para o desenvolvimento empírico de tal questão, será explorado o "caso" do sistema prisional do estado de São Paulo, onde nos anos de 1980, durante o governo Montoro, as autoridades estimularam a formação de Comissões de Solidariedade dos presos (que tiveram existência formal breve) e onde depois surgiu, na década seguinte, o grupo autodenominado Primeiro Comando da Capital (PCC), que se mantém atuante ainda no presente. Embora situados em contextos políticos e sociais diferentes, pretende-se, com a análise comparativa da emergência desses dois acontecimentos no interior do sistema prisional paulista, desenhar a hipótese de que a obstrução à existência de mecanismos de comunicação e representação da população carcerária efetivamente legitimados pelas autoridades, no período da transição democrática, favoreceu a formação de um grupo de presos que se impôs pela violência mas que, ao mesmo tempo, buscou fundamentar sua "legitimidade" na representação dessa população, com base nas denúncias das deficiências do sistema prisional e também a partir dos códigos de conduta formulados no mundo do crime.

Num primeiro momento será feita revisão de parte da literatura nas ciências sociais que explorou o tema das formas de organização dos presos no interior das prisões nos âmbitos internacional e nacional. Em seguida, serão caracterizados os dois momentos em jogo: primeiro, a experiência da formação em algumas penitenciárias paulistas de grupos representantes dos 
presos que ficaram conhecidos como Comissões de Solidariedade; depois, a emergência e a atuação do PCC, que é ainda hoje um dos principais desafios para a segurança pública no estado. Para finalizar, são apontados alguns desdobramentos de pesquisas que exploram o problema da ação coletiva dos presos no sistema prisional paulista a partir de uma perspectiva temporal mais ampla, abrindo espaço também para a discussão política de formas legítimas de ação coletiva dos presos que não deságuem necessariamente em comportamentos ilegais e violentos como os encontrados nos dias atuais.

\section{Revendo a literatura internacional}

Os estudos sobre as dinâmicas prisionais quase sempre estiveram associados à própria discussão pública acerca do papel da prisão como instituição punitiva, com suas crises e tentativas de reforma. Assim, foram as instabilidades internas que abalaram as prisões norte-americanas ao longo dos anos de 1950, que estimularam vários estudos no campo das ciências sociais voltados, sobretudo, para a compreensão das formas de organização dos presos e de suas relaçôes com os custodiadores. É desse período um dos maiores clássicos da literatura prisional, The society of captives, de Gresham M. Sykes $\left([1958]^{*} 1974\right)$, cuja análise focaliza a prisão como um sistema social que emerge a partir das interações entre os presos e entre estes e os guardas. Para Sykes, a chave para a compreensão do funcionamento desse sistema é a falha estrutural da instituição prisional, na medida em que é incapaz de impor o poder total sobre a população carcerária, tal como oficialmente pretende. A partir dessa falha é que se podem compreender os acordos, as negociações e a divisão de poder que efetivamente movem esse sistema de ação entre custodiadores e presos. A ordem mantida na prisão é, desse ponto de vista, sempre precária, instável e sujeita à ruptura dos acordos. Sykes colocou em evidência a trama das interações que se constroem no interior das prisões e permitem compreender as possibilidades de manutenção da ordem e de alcance de alguns dos objetivos esperados pela sociedade.

Erving Goffman ([1961] 1974) analisou essas interações - no interior do que denominou, de forma mais geral, de instituiçôes totais - como um campo de possibilidades de trocas, de barganhas e de acomodaçóes envolvendo basicamente dois grandes grupos: os presos e os custodiadores. Sua ênfase também recaiu sobre a vida cotidiana da instituição, com a predominância de arranjos não oficiais que delimitam o campo de ação desses dois grupos de acordo com sua posição institucional. Goffman criou uma tipologia para
* A data entre colchetes refere-se à edição original da obra. Ela é indicada na primeira vez que a obra é citada. Nas demais, indica-se somente a edição utilizada pelo autor (N.E.). 
compreender as ações no interior de instituições como a prisão, dividindo-as em ajustamentos primários e secundários. $\mathrm{O}$ ajustamento primário seria o comportamento do indivíduo quando contribui cooperativamente para uma organização e as atividades por ela exigidas. O secundário, por sua vez, seria aquele em que o membro da organização utiliza meios não legítimos e visa atingir objetivos não sancionados pela instituição, ou seja, emprega meios ilícitos e busca fins não autorizados de forma a escapar daquilo que a organização supõe que ele deve ser. Dadas as características da instituição prisional - instituição de mortificação do "eu", como outras instituições totais -, a maior parte da dinâmica institucional envolvendo presos e custodiadores seria compreensível em termos sobretudo dos ajustamentos secundários que predominam no cotidiano prisional.

Autores como Clarence Schrag (1954), em outra direção, discutiram a importância da identificação dos líderes entre a população carcerária, bem como dos mecanismos de formação dessas lideranças. O objetivo da autora era conhecer o processo de formação das lideranças para que administração prisional pudesse controlá-lo, fomentando determinados líderes em detrimento de outros ou promovendo o isolamento das lideranças consideradas negativas ou daqueles cujo perfil indicava possibilidade de resistência a essas lideranças.

A discussão dos aspectos formais e informais da prisão constitui-se igualmente em questão central no texto de Bernard B. Berk (1966). Comparando três instituiçôes classificadas e graduadas de acordo com a ênfase na custódia ou no tratamento e categorizadas como fechada, parcialmente fechada e aberta, ele analisou as diferenças em termos da organização informal em cada uma delas. Apontou, ainda, que as atitudes dos presos tendiam a ser mais positivas e cooperativas com a administração nas instituições abertas, voltadas ao tratamento. Os líderes desempenhavam papel diferente de acordo com a tendência da instituição: nas mais abertas, tendiam a cooperar e, nas mais fechadas, a tendência era o surgimento de lideranças mais negativas e em flagrante oposição à administração formal. Em suma, o autor mostra que os objetivos e o modo de organização formal das instituições determinam a sua organização informal, incluindo as atitudes dos presos em relação à própria instituição.

Já Charles R. Tittle (1969) utilizou o método comparativo para discutir se a organização social dos presos é um produto institucional ou se é a transposição da subcultura criminal para o interior das prisões. Nesse sentido, analisou as formas de organização social dos presos em termos do sexo e concluiu que, embora haja diferenças significativas entre presos homens e mulheres - so- 
bretudo na construção de grupos primários e de forte apelo afetivo por estas últimas, ao passo que os homens tendem a se associar em grupos maiores, privilegiando aspectos financeiros e sexuais -, quanto à sua organização, elas são paralelas e não exclusivas. Isso, para o autor, confirmou a teoria de que a dinâmica da organização dos presos é sobretudo um produto institucional.

As experiências de envolvimento dos presos na condução dos assuntos internos da prisão, promovidas pelas autoridades, decorreram da constatação de que não seria possível "ressocializar" os criminosos impondo a eles um modo de vida completamente artificial e sem qualquer exercício de responsabilidade durante a permanência na condição de encarcerados. Essa perspectiva foi traduzida pela sociologia em termos de análise da prisão como "comunidade". Diversos estudos norte-americanos tomaram esse rumo (cf. Clemmer, [1940] 1958; Hayner e Ash, 1939). Além de ser acionada como um conceito que permitia compreender os processos sociais internos (conflitos, relaçóes sexuais, isolamento etc.), a ideia de comunidade proporcionaria sustentação como princípio para implementar iniciativas de ajustamento das prisōes aos objetivos estabelecidos pela sociedade. Segundo Norman S. Hayner e Ellis Ash (1939, p. 580), "prisões foram ineficazes para ajudar criminosos a se tornarem cidadãos cumpridores da lei” na medida em que elas não proporcionavam oportunidades de participação dos presos na condução de sua vida interna, nem promoviam situações de integração que permitissem um sentimento de pertencimento àquela coletividade.

Mais recentemente, Richard J. Sparks e Anthony E. Bottoms (1995), sob o impacto da onda de motins nas prisões britânicas, defenderam a necessidade de discutir a manutenção da ordem nessas instituiçôes a partir da teoria da legitimidade. Para eles, ainda que se trate de um regime de força, a ordem nas prisões pode ser afetada, positiva ou negativamente, de acordo com a forma como as regras são aplicadas, da justiça dessas regras em termos das crenças compartilhadas pelos sujeitos e do tratamento humano e digno do preso. Um regime prisional legitimado demanda um diálogo no qual a voz dos presos é ouvida e, ainda, deve ter por referência padrôes que podem ser defendidos externamente, a partir de argumentos políticos e morais. Para os autores, a legitimidade coloca-se não apenas em termos normativos, mas também pela sua importância na manutenção e reprodução da ordem social na prisão.

$\mathrm{Na}$ França, também a reflexão sobre a prisão acompanhou as urgências e as crises provocadas pelas próprias dinâmicas prisionais. A perspectiva crítica elaborada por Michel Foucault foi formada, sobretudo, com a crise 
de legitimidade das instituições prisionais a partir de maio de 1968, acompanhada pelo posterior endurecimento das políticas de segurança do governo francês no início dos anos de 1970, o que levou à prisão de militantes de esquerda e desembocou numa onda de motins que atingiu os estabelecimentos franceses na época.

Foucault é mais conhecido por seu livro Vigiar e punir (1987), em que, na esteira do trabalho de Georg Rusche e Otto Kirchheimer (1939), analisou o papel central da prisão na penalidade moderna. Nesse livro, o filósofo francês estava preocupado sobretudo em caracterizar o poder disciplinar, poder voltado para o "adestramento" dos indivíduos, que tem nas prisões modernas um de seus espaços exemplares de aplicação. A elaboração desse livro, no entanto, foi em parte resultado da participação de Foucault na mobilização que deu origem ao Groupe d'Information sur les Prisons (GIP), criado em 1971 e que contava também com o envolvimento de Pierre Vidal-Naquet e Jean Marie Domenach (cf. Artières et al., 2003; Artières, 2004; Eribon, 1990; Alvarez, 2006). O GIP se constituiu como um novo tipo de mobilização que buscava dar a conhecer publicamente a situação das prisōes francesas, ao reunir numerosos testemunhos e escritos produzidos principalmente pelos próprios presos. A criação do GIP propiciou naquele momento um intenso debate público sobre as condições de silenciamento a que estavam submetidos os presos e sobre os obstáculos que se colocavam entre a prisão, os presos e a sociedade, não só ao denunciar as condições por vezes inadequadas de encarceramento, mas sobretudo ao dar voz aos presos, tornar visíveis seus rostos, sua existência atrás das grades. O grupo formado em torno do GIP não buscou estimular as revoltas que se seguiram nas prisões francesas, mas indicar como essas manifestaçōes eram esperadas diante das condições existentes de encarceramento, abrindo espaço para a análise das novas formas de subjetividade coletiva, pois, ao se sublevarem, os presos acabavam por se constituir em força coletiva ante a administração prisional.

Diversos outros trabalhos surgiram na França, desde o início dos anos de 1970, com uma perspectiva mais analítica do sistema prisional, como por exemplo os de Combessie (2001), Chantraine (2006a) e Artières (2004), ou ainda o de Antoinette Chauvenet et al. (1994) sobre os agentes penitenciários e o de Corine Rostaing (1997) sobre as mulheres presas. Na linha dos escritos de denúncia das condiçôes de encarceramento na França, o da médica Véronique Vasseur (2000) provocou intenso debate público e constrangimento às autoridades ao descrever a situação precária dos presos na prisão La Santé, que funciona no centro da capital da república francesa. 
Utilizando-se da contribuição analítica deixada por Foucault, Chantraine (2006b) observa que, ao lado da recente tendência de confinamento extremamente rígido adotado em muitas prisões, com severas limitações de locomoção, atividades e contatos com o mundo exterior, surgem também novos padrões de organização interna das instituições, que o autor denominou de prisão pós-disciplinar ou governamentalizada. Tendo por base uma experiência prisional do Canadá, Chantraine mostra que ali os presos são instados pela própria administração do estabelecimento a nomear representantes, constituir lideranças que negociem suas demandas com o Estado, ao estabelecer uma complexa mecânica de privilégios, concessóes e restrições. Segundo ele, a colaboração dos presos é estimulada na expectativa de infundir sentimentos de cooperação, de responsabilidade e de autonomia. No entanto, os direitos dos presos são objeto de constante negociação por parte da administração, condicionados aos riscos ou ao rompimento provocados pelos presos nos seus compromissos de gestão autônoma. Técnicos e gestores buscam manter a ordem interna por meio de mecanismos participativos que levem os presos a se autogovernarem, minimizando, em consequência, o recurso aos dispositivos coercitivos. Segundo Chantraine, porém, a organização e autogestão dos presos estão sempre subordinadas, e são facilmente desativadas diante dos riscos à manutenção da ordem e da segurança interna e externa.

Em suma, da literatura norte-americana sobre a prisão como um sistema social próprio às abordagens críticas como as de Foucault - voltadas para a caracterização do poder disciplinar e para as formas de resistência que emergem correlativamente a esse poder -, não só novos campos de investigação se abriram para a caracterização das dinâmicas sociais no interior da prisão, mas igualmente ganhou relevo a necessária discussão pública acerca da criação de canais legítimos de representação da população carcerária. No Brasil, também a reflexão sociológica trabalhou tais questôes, espelhando-se, em parte, na literatura internacional, mas articulada ao mesmo tempo ao contexto social e político específico desenhado pela situação das prisões brasileiras.

\section{A reflexão no Brasil}

No Brasil, a literatura das ciências sociais sobre as prisões recebeu grande influência norte-americana, mas só se destacou efetivamente a partir do final dos anos de $1970^{1}$. O trabalho pioneiro de José Ricardo Ramalho (1979) constrói a análise da Casa de Detenção de São Paulo (Carandiru)
1. É necessário reconhecer que, na passagem do século XIX para o XX, médicos e juristas já esboçavam trabalhos de natureza sociológica e antropológica sobre as prisóes no país, uma vez que essas áreas ainda não haviam se constituído como campos institucionalizados e autônomos em relação aos tradicionais cursos de direito e de medicina. Paulo Egydio (1896), Aurelino Leal (1902) e Nina Rodrigues ([1894] 1957) podem ser citados como exemplos de autores que desenvolveram alguns estudos nessa direção. Sobre as relaçōes entre o campo da criminologia e das ciências sociais no Brasil, ver Alvarez (2003) e Candido (1958), e sobre a formação das ciências sociais no período, ver Miceli (1989) e Chacon (1977). 
em torno da dicotomia "mundo do trabalho" versus "mundo do crime", que se refletia não apenas nos valores e no comportamento de presos e funcionários, mas na própria repartição física da Detenção: o pavilhão 2, reservado aos presos que trabalhavam, compunha o polo de uma oposição que tinha, na outra ponta, os pavilhōes 8 e 9, o chamado "fundão", o que expressava uma divisão muito mais estrutural do que temporária ou acidental. Essa divisão opunha os chamados criminosos ocasionais - para os quais haveria recuperação - e os criminosos natos, irrecuperáveis.

No início da década de 1980, Edmundo C. Coelho (1987) realizou um estudo sobre o sistema penitenciário do Rio de Janeiro que é até hoje referência na área. Com forte influência de Sykes (1974), Coelho discutiu as contradições inerentes à instituição prisional no que refere aos seus objetivos - recuperar e punir - e ao seu funcionamento: imposição de poder e necessidade de cooperação por parte dos presos. Enfatizou também o importante papel das lideranças da população carcerária para a manutenção da ordem, bem como a erosão do poder da administração que a necessidade de fomentar e negociar com essas lideranças implicava.

A pesquisa empírica de Coelho ocorreu num momento político suigeneris no Rio de Janeiro, com a eleição de Leonel Brizola e sua tentativa de democratização do sistema prisional. Entre outras ações nessa direção está a tentativa de implantar uma comissão de presos para dialogar com a administração prisional e participar de algumas decisões. Essas comissōes, contudo, acabaram sendo ocupadas por lideranças de quadrilhas e servindo de mote para intensas e sangrentas disputas entre os grupos que já se organizavam nas prisões cariocas nesse período. Isso tudo, obviamente, acompanhado - e fomentado - por enorme descontentamento dos funcionários e diretores, que consideravam estar perdendo poder, uma vez que o Estado procurava regulamentar as práticas sociais nas prisões. A onda de violência que assolou o sistema carcerário carioca nesse período foi suficiente para que as medidas democratizantes do governo Brizola fossem apontadas como as causas para a crise no setor, e uma forte pressão popular alimentada pelos setores políticos mais conservadores acabou por revogar o processo de abertura, inédito, em marcha no estado.

Coelho discutiu todas essas questôes e apontou como inócua qualquer tentativa de fazer da instituição prisional algo diferente de um sistema calcado na violência, uma vez que esse elemento seria inerente a qualquer estabelecimento prisional e, no Brasil em geral e no Rio de Janeiro em particular, a situação seria ainda mais dramática, na medida em que o Estado não cumpriria seu papel na provisão dos bens necessários à sobrevivência na 
prisão, forçando o desenvolvimento de uma economia ilegal nesses estabelecimentos. Isso acabaria por minar a autoridade e a legitimidade do poder público em aplicar qualquer programa de ressocialização, restando-lhe tão somente a força para evitar rupturas mais graves.

A par de perceber a atuação das organizações de presos como central na análise desenvolvida na sua principal obra (cf. Coelho, 2005), o autor abordou em um texto imediatamente posterior a trajetória e as transformaçôes da principal organização criminosa do Rio de Janeiro, o Comando Vermelho, em especial no tocante ao perfil de suas lideranças, que resultariam numa mudança significativa na sua forma de atuar. Coelho apontou como as lideranças que fundaram a organização, compostas por assaltantes de bancos, foram sendo substituídas por traficantes. Isso acarretou profundas mudanças na facção. Em primeiro lugar, porque os traficantes não têm fortes vínculos com a massa carcerária, na medida em que fogem regularmente das prisões e, principalmente, mantêm sua "empresa" em pleno funcionamento, mesmo quando estão encarcerados - o que não ocorre com o assaltante de banco, que cessa de ganhar dinheiro tão logo vai para a cadeia. $O$ poder normativo exercido pelos assaltantes - baseado num discurso e numa ação que enfatizava a necessidade de união dos presos contra a violência institucional e a luta por seus direitos - foi transformado num poder remunerativo exercido pelos traficantes, que passaram a fazer promessas pontuais efetivadas com o dinheiro de seus negócios, como melhorias nas instalações das unidades prisionais, promoção de jogos e festas, pequenos favores, remuneração a pequenos serviços pessoais e promessa de inserção na rede do tráfico, sem hostilizar abertamente o poder público (cf. Idem, pp. 38-39).

Uma das contribuiçôes mais significativas para o debate sobre a emergência de grupos criminosos organizados nas prisôes brasileiras foi dada por Antônio Luiz Paixão com o livro Falanges vermelhas, serpentes negras e a ordem prisional (1987). Sua reflexão é contemporânea ao intenso debate público que se instalou em meados dos anos de 1980, à medida que avançavam as iniciativas de modificação das políticas prisionais no Rio de Janeiro, em São Paulo e Minas Gerais. Tais políticas tinham em comum a busca da alteração dos padrões de administração consolidados durante o regime militar e, portanto, traziam uma preocupação com a redução da violência e da arbitrariedade nos ambientes prisionais e o estímulo à participação dos presos numa perspectiva de promoção e defesa de seus direitos.

$\mathrm{O}$ argumento principal de Paixão era que as organizaçôes criminosas de presos que então se formavam não decorriam da leniência das políticas de 
humanização dos presídios, como propalavam seus opositores, mas antes de uma dinâmica própria do que chamou de modernização da criminalidade urbana. Assalto a banco e tráfico de drogas eram modalidades criminosas que impunham níveis mais elevados de organização e de eficiência para seu sucesso. As tais falanges, comandos, serpentes, segundo ele, nada mais seriam que "padrões organizacionais e reivindicatórios que acompanham a modernização do comportamento criminoso nas áreas metropolitanas brasileiras e que alteram a estrutura das populações prisionais" (Paixão, 1987, p. 77). Essas organizações anunciavam "um novo modelo de negociação de ordem" prisional que confrontava diretamente com os padrôes então vigentes de manutenção dos ambientes prisionais.

Em suma, Paixão desvinculou a formação de grupos criminosos organizados, inclusive no interior das prisōes, das políticas "liberais" que foram adotadas em meados da década de 1980. Formas mais rigorosas de manutenção do cotidiano prisional também não evitaram a formação de grupos organizados. Para ele, como já afirmado, a formação desses grupos se deveria às características mais gerais da própria criminalidade. $\mathrm{E}$ as prisóes, como qualquer outra formação social, leva à constituição de grupos e de lideranças que disputam o controle sobre os recursos e as oportunidades que o ambiente proporciona. Nesse sentido, a ação desses grupos na prisão não significaria absolutamente a promoção da representação dos interesses do grupo maior, no caso os presos.

Depois dessas reflexões, realizadas na década de 1980, a questão da organização dos presos foi retomada no Brasil a partir das análises sobre as rebeliōes. A abordagem das rebeliōes esteve, em geral, associada às análises de contextos sociais e políticos e/ou das políticas penais que teriam influência (ou não) sobre tais eventos. Nessa perspectiva, pode-se destacar o trabalho de Eda Góes (1991) sobre as rebelióes ocorridas durante a década de 1980 em São Paulo. Para a autora, esses eventos eram decorrentes das mudanças políticas pelas quais o Brasil estava passando no período - transição do regime autoritário para a redemocratização - e, assim, estariam ligados ao descontentamento de alguns setores da sociedade, em especial dos servidores do sistema penitenciário, com as políticas liberalizantes, que ficaram conhecidas como política de humanização dos presídios.

Sérgio Adorno e Fernando Salla (s/d) realizaram uma pesquisa sobre as rebeliôes em São Paulo no período de 1995 a 2000, classificando-as em termos do número de presos envolvidos, da sua duração, número de mortos e ação da administração prisional. Entre as conclusões desse estudo está a identificação da grande instabilidade pela qual passava o sistema carcerário 
no período e da nova conformação das rebeliōes, deflagradas principalmente pela disputa entre os grupos criminosos que se expandiam no interior do sistema carcerário, causando um grande número de vítimas, não mais pela ação da polícia - como fora na década anterior -, mas pela ação dos próprios presos.

Salla (2006) agrupou as rebeliōes em três períodos, que de certa forma refletem diferentes formas de organização e atuação dos presos: o primeiro, até o início dos anos de 1980, cuja característica principal foi o protesto contra a precariedade das condiçôes de encarceramento; o segundo período, que compreenderia a década de 1980, cujos eventos de ruptura nas prisões estariam ligados à conivência, omissão ou mesmo incentivo de setores políticos e administrativos refratários à tentativa de humanização dos presídios, empreendida especialmente pelo governo Montoro, em São Paulo; por fim, o terceiro período, correspondente à década de 1990, marcado pela atuação dos grupos criminosos organizados no comando das rebeliôes. As rebeliôes em São Paulo que emergiram nos anos de 1990 teriam como elementos importantes tanto a precariedade das prisões como a ausência de controle da massa carcerária por parte do Estado, o que favoreceu a expansão do domínio dos grupos criminosos organizados no interior dos estabelecimentos prisionais.

\section{Das Comissões de Solidariedade ao PCC}

Como se observou, as formas de organização dos presos ocuparam parte importante da literatura internacional das ciências sociais sobre as prisões. No Brasil, a conjuntura política de transição do regime autoritário para a democracia nos anos de 1980 abriu amplo debate público sobre as prisōes e fomentou igualmente a reflexão de cientistas sociais. Além das questôes relativas à precariedade das condiçôes de encarceramento e da violência institucional enraizada nas prisóes, instalou-se um amplo debate sobre as formas de representação dos presos, de garantia dos seus direitos, sobretudo com a entrada em vigor da Lei de Execução Penal (Lei 7210, de 1984). A agenda de democratização de tais espaços, que motivaria a proposta de representação dos próprios presos na defesa de seus direitos, enfrentava a herança autoritária ainda presente nas instituições de segurança pública e a resistência política de amplos setores da sociedade, bem como a emergência de uma nova criminalidade.

Em 1983, assim que assumiu o governo do estado de São Paulo, o governador Franco Montoro designou como secretário de Justiça José Carlos Dias, que tinha como uma das principais tarefas implementar uma nova 
2. As comissōes foram bastante ativas em duas unidades prisionais: Penitenciária do Estado e Penitenciária de Araraquara. política para o sistema penitenciário. Ela ficou conhecida como Política de Humanização dos Presídios e tentava reverter as arbitrariedades e violências praticadas nas prisões, sobretudo sob a proteção do regime militar. Uma das iniciativas mais interessantes dessa política foi a constituição, em algumas penitenciárias, de grupos representantes dos presos, que ficaram conhecidos como Comissões de Solidariedade ${ }^{2}$.

Inseridas no contexto de uma política de extensão dos princípios democráticos às instituições prisionais, as Comissões de Solidariedade constituíram-se como canais diretos de comunicação entre os presos e a Secretaria de Justiça e os juízes corregedores (cf. Góes, 1991, p. 19). Através das comissões, os presos encaminhavam as demandas relativas às condições de cumprimento da pena de prisão e as reivindicações em termos do acesso aos direitos e sua garantia.

A proposta de criação das Comissões de Solidariedade situava esses grupos no registro normativo-legal da luta por direitos. Nesse sentido, essa proposta rejeitava tanto as formas "pelegas" de representação, em que os "representantes" eram indicados pela administração local, como também as formas tradicionais de cooperação entre a administração prisional e as lideranças "naturais" dos presos, constituídas a partir da sua ascendência no mundo do crime. Em contraposição, o regimento da Comissão de Solidariedade da Penitenciária do Estado previa a eleição direta de seus integrantes através do voto secreto, garantido a toda população carcerária, e tornava inelegíveis os presos acusados de cometer atos de violência contra companheiros ou funcionários (cf. Idem, p. 23).

Significativamente, as Comissóes de Solidariedade foram o alvo principal da campanha de oposição à política de humanização das prisões, que teve início já em 1984. Ao contar com o apoio da ampla maioria do staff prisional, setores do Judiciário, partidos políticos (inclusive setores do partido do governador) e parte da imprensa paulista (cf. Idem, ibidem), o movimento de oposição às políticas de José Carlos Dias não tardou a produzir efeitos, sobretudo sobre as comissões, deslegitimando-as.

O principal ataque contra as comissões surgiu com a denúncia da existência de um grupo de presos matadores, denominado Serpentes Negras, que tinha como objetivo dominar a massa carcerária via Comissão de Solidariedade. Embora a existência do grupo Serpentes Negras nunca tenha sido comprovada, muito menos a sua incidência sobre a comissão, as denúncias tiveram importância suficiente para esvaziar a primeira experiência brasileira de constituição de uma instância de representação dos presos, ao deslegitimar 
sua atuação como um canal de comunicação entre a população carcerária e os responsáveis pela gestão das políticas prisionais.

Segundo a análise de Góes (1991), as formas de manifestação de insatisfação com a direção dos estabelecimentos prisionais através das Comissões de Solidariedade encontravam algum respaldo na nova política de direitos humanos que vinha norteando as atitudes da Secretaria de Justiça. Nesse sentido, eram priorizadas formas de negociação e acordos formais entre os presos e a administração prisional, nos quais a violência, que normalmente acompanha esses movimentos reivindicatórios, pudesse ser reduzida de maneira significativa. Contudo, diante do bloqueio ou, pode-se dizer, do boicote a esses novos canais de reivindicações, os presos retomaram os métodos violentos já tradicionais que marcam as rebeliôes ou motins.

Ainda de acordo com essa autora, a causa da eclosão de rebeliôes carcerárias vai muito além dos aspectos imediatos e pontuais que marcam as demandas dos presos, como a redução da superpopulação ou a melhora da infraestrutura dos estabelecimentos. A exposição desses problemas, embora eles estejam quase sempre presentes na pauta de reivindicações dos presos, acaba por encobrir aspectos determinantes na forma pela qual as demandas são explicitadas. Assim, a ausência de canais de representação capazes de canalizar o descontentamento da população carcerária apresenta-se como um elemento central dos distúrbios nas prisões, sendo as rebeliōes seu efeito mais expressivo.

As dificuldades de implementação da política de humanização dos presídios ficaram evidentes ainda durante o governo Montoro, com a saída do secretário José Carlos Dias. Nos governos seguintes, de Orestes Quércia e de Luiz Antonio Fleury Filho, assistiu-se a uma verdadeira guinada conservadora na área da segurança pública paulista, com a reversão de praticamente todas as experiências de abertura dentro do sistema prisional formuladas no início da gestão Montoro. Em termos práticos, essa (re)orientação política provocou efeitos desastrosos, com uma escalada da violência cujo ápice foi o Massacre do Carandiru em 1992 (cf. Salla, 2006, 2007).

No ano seguinte ao massacre, surgiu o grupo de presos autodenominado Primeiro Comando da Capital (PCC), considerado um dos principais desafios para a segurança pública de São Paulo. Criado no interior do Anexo da Casa de Custódia de Taubaté, presídio que representava o que de mais arbitrário havia no sistema carcerário paulista, o PCC surge ancorado no discurso da união entre os presos como forma de luta contra a opressão perpetrada pelo Estado. De acordo com um de seus fundadores: 
3. José Márcio Felício dos Santos, em depoimento à Comissão Parlamentar de Inquérito (CPI) do Tráfico de Armas, em 17/5/2005, p. 56. Geleião, como é conhecido, foi um dos fundadores do PCC e até 2002 permaneceu como a principal liderança do grupo, ao lado de César Augusto Roriz, o Cesinha.
4. Depoimento de Marcos William Herbas Camacho, o Marcola, à Comissão de Combate à Violência, da Câmara dos Deputados, prestado em 21/8/2001, resumido no relatório final da comissão, p. 126. Marcola é apontado como um dos principais líderes do PCC desde 2002, após o rompimento com os fundadores Geleião e Cesinha. $\mathrm{Na}$ ocasião dessa declaração, portanto, a referida cisão ainda não tinha ocorrido.
Nós surgimos dentro da prisão, porque, na verdade, nós não esperávamos que o PCC crescesse dessa maneira, porque a nossa luta era interna. Era para combater as injustiças que sofríamos, porque, na época, a injustiça era demais e não adiantava reclamar para as autoridades, não adiantava reclamar para ninguém ${ }^{3}$.

Narrativa sobre o surgimento do PCC que é muito próxima do discurso de outro importante integrante da organização:

Em 1993, foi fundado o PCC em Taubaté, que é um presídio onde o tratamento é igual a esse local onde me encontro hoje [Penitenciária da Papuda, DF], nesse pavilhão de segurança máxima, ou seja, o cara é totalmente isolado do resto da população carcerária, não tem direito a ver tevê, não tem direito a rádio, não tem direito a estudar, não tem direito a trabalhar, não tem direito a nada do que reza o Código de Execuções Penais. Não tenho direito a nada, e já não tinha em 1991, 1992 e 1993, quando foi fundado o PCC. Então, o PCC foi fundado por isso e por causa da chacina do Carandiru, onde foram assassinados 111 presos. Estou dentro de uma prisão onde morrem 111 presos. Eu me sinto inseguro, doutor. O PCC foi fundado porque não tinha para onde correr. Se a gente reclama, se a gente manda ofício, ninguém toma nenhuma atitude, ninguém olha para o preso, principalmente porque é pobre .

Para além das denúncias de maus-tratos, violências e arbitrariedade do Estado diante da população carcerária como elementos centrais na conformação do discurso legitimador do PCC, chama atenção nesses dois depoimentos a menção à ausência de canais de comunicação entre os presos e as autoridades responsáveis pela administração prisional. Nas duas narrativas aponta-se o fracasso das tentativas de denunciar as arbitrariedades de funcionários e diretores de presídios e de reivindicar o cumprimento da Lei de Execução Penal (LEP) pelo Estado, sobretudo no que tange ao respeito aos direitos dos presos e garantia de sua integridade física.

Pode-se considerar, portanto, que foi no vácuo deixado pela ausência de uma instância representativa da população carcerária e da completa obstrução dos canais de comunicação entre os presos e a administração prisional que o PCC encontrou um espaço para se constituir e se legitimar como alternativa ao isolamento dessa população diante de suas demandas - muitas das quais, sem dúvida, legítimas - e a sua luta por direitos e reconhecimento.

Independentemente das condições em que se produz a representação dos presos através do PCC (e se ela existe), o fato é que o discurso da luta contra a opressão do Estado e pela garantia de direitos foi apropriado com 
muito êxito por esse grupo e se tornou sua base de apoio social e político. Com a consolidação de seu poder sobre a população carcerária, por meio de um complexo processo que envolveu sangrentas disputas, acordos e acomodações (cf. Dias, 2011), o PCC se consolidou como uma importante força social e política. Organizado em torno de atividades ilegais e contando com forte apoio das bases sobre as quais se assenta o seu domínio, coloca-se como um ator com o qual o Estado, querendo ou não, tem que lidar e cujas reivindicações devem fazer parte (de forma direta ou indireta) das pautas e dos debates sobre a política para o sistema prisional.

O PCC passou a habitar, pois, os espaços sociais onde as regras, os valores, os recursos e os objetivos das políticas públicas para o sistema prisional são disputados, apropriados ou rejeitados (cf. Neves, 1993), constituindo-se como ator político, provocando constrangimentos e impondo ao governo estadual a necessidade de recorrer a alternativas políticas específicas, seja para tentar enfraquecer ou desarticular a organização, seja para manter acomodaçôes e garantir a estabilidade social. Isso porque, conforme afirma Neves,

\begin{abstract}
[...] a emergência de novos atores a partir da organização de seus interesses acarreta alterações qualitativas nas relações entre as instâncias estatais e a classe dominante, [pois] organizando-se em resposta a interesses e questôes diversas, os agentes em disputa podem deslocar a concorrência para instâncias e campos de regras diferentes, alterando as consequências e os desdobramentos dela (concorrência) advindos (Idem, p. 80).
\end{abstract}

A partir de 2001, em resposta ao surgimento do PCC, o governo paulista adotou estratégias formais e informais visando o enfrentamento da organização. No plano formal, a principal medida foi a criação, pela Secretaria de Administração Penitenciária, do Regime Disciplinar Diferenciado (RDD), por meio da Resolução SAP 26/01, que, em 2003, foi transformada em Lei Federal (Lei 10792/03), incorporada à Lei de Execução Penal ${ }^{5}$. Trata-se de um regime de cumprimento da pena de prisão muito mais rígido em termos disciplinares, com uma hora de banho de sol, ausência de visita íntima, controle estrito da comunicação com advogados e visitantes, isolamento celular sem acesso a televisão e rádio e acesso restrito a livros, revistas e jornais. Entre as condutas passíveis de penalização através da internação no RDD está a suspeita de participação em “organização criminosa”, e 360 dias é o período máximo de permanência no regime (sem prejuízo de repetição da sanção em caso de nova falta grave, até o limite de $1 / 6$ da pena $)^{6}$.

\footnotetext{
5. Para uma discussão acerca dos efeitos do RDD na dinâmica prisional, ver Dias (2009).

6. Em termos das medidas de enfrentamento ao PCC, além da criação desta sanção no âmbito da execução penal, destaca-se a atuação do Ministério Público Estadual e da polícia civil no desmantelamento de centrais telefônicas e no bloqueio de centenas de contas correntes que eram utilizadas para movimentar o dinheiro da facção.
} 
7. De acordo com Souza (2007, pp. 30-31), perícia da polícia civil apontou que o estatuto do CRBC foi escrito na sala de um diretor da penitenciária. Além disso, presos mencionaram em entrevistas (ver Dias, 2011) diversos episódios de "tomadas" de cadeias - isto é, substituição da facçāo detentora do controle local - fomentados e/ou apoiados pela direção da unidade.
No plano informal, uma das açóes da administração penitenciária parece ter sido a tentativa de provocar a fragmentação do poder do PCC estimulando a formação de outros grupos que poderiam se tornar rivais. Conforme sugerido por alguns autores e de acordo com relatos de presos, o Comando Democrático da Liberdade (CDL) teria sido criado na Penitenciária I de Avaré, com a colaboração direta da direção da unidade, e o Comando Revolucionário Brasileiro da Criminalidade (CRBC) teria sido concebido dentro da Penitenciária Parada Neto, de Guarulhos ${ }^{7}$. Juntamente com o PCC, esses grupos foram protagonistas de uma série de confrontos violentíssimos durante o início dos anos 2000. O CDL, contudo, foi praticamente dizimado e o CRBC permanece restrito a poucas unidades prisionais, mantendo seu reduto na penitenciária que se constituiu como seu berço.

Outra ação voltada para o enfrentamento ao PCC, que pode ser situada numa zona "cinzenta” entre o legal e o ilegal, deu-se por meio do Grupo de Repressão e Análise dos Delitos de Intolerância (Gradi). Em 2001, esse grupo passou a atuar em ações contra o PCC ao lado das Agências Regionais de Inteligência (ARIs) da PM paulista. Com o respaldo de setores do Judiciário, o Gradi passou a realizar ações arbitrárias e ilegais, como grampos telefônicos, torturas, sequestros e recrutamento, e infiltração de presos e de policiais em ações criminosas ligadas ao PCC (cf. Jozino, 2005, pp. 156-157). Entre as açóes do Gradi, a que ficou mais conhecida foi a Operação Castelinho, em março de 2002, que culminou com a execução de doze supostos integrantes do PCC pela Polícia Militar, numa emboscada no trajeto para execução do assalto a um avião pagador em Sorocaba. $\mathrm{O}$ aviāo pagador não existia e tudo não passava de uma farsa armada pelo Gradi, com a conivência de alguns juízes e promotores, bem como da Secretaria de Segurança Pública e da direção da Penitenciária I de Avaré, de onde eram retirados os presos ilegalmente infiltrados nessas operações.

Se, em relação ao PCC, uma das estratégias principais da administração penitenciária foi a criação e o fortalecimento de grupos rivais que pudessem opor resistência à sua expansão no interior do sistema penitenciário paulista, nos anos de 1980 as estratégias do governo em relação à Comissão de Solidariedade eram no sentido de seu fortalecimento. A Secretaria da Justiça, na época, buscou transformar a Comissão de Solidariedade num legítimo interlocutor para a condução dos assuntos internos à prisão. Para tanto, tentou tornar seu funcionamento o mais transparente possível, dando-lhe inclusive um regulamento que estipulava as condições de participação dos presos, evitando, ao mesmo tempo, que a comissão fosse acusada de servir a outras 
finalidades que não a representação dos presos e a colaboração com a gestão da unidade prisional. Outra estratégia da secretaria foi trazer uma assessora para acompanhar diretamente a instalação e as atividades da comissão, de modo que conseguisse estabelecer um elo legítimo entre presos, direção local da unidade prisional e administração superior. Essa assessora teve papel fundamental na gestão dos principais conflitos que foram emergindo, sobretudo da parte dos guardas penitenciários que viam na existência da comissão, nas suas tentativas de reduzir as arbitrariedades no cotidiano prisional, uma forma de diminuição de seu poder sobre os presos. Mesmo quando as Comissões de Solidariedade foram acusadas de servir de canal para a formação de organizações criminosas, como o grupo Serpentes Negras, a administração superior da Secretaria da Justiça saiu em sua defesa e abriu investigação interna para apurar as denúncias. Além disso, a secretaria, acreditando nas comissóes como uma forma de redesenhar as políticas de gestão penitenciária, ao reduzir a violência e estabelecer uma pauta de respeito aos direitos humanos, mobilizou esforços com várias organizações da sociedade civil para uma ação política ampla, nos meios de comunicação principalmente, em defesa das comissões e para o questionamento da denúncia da proliferação de organizações criminosas.

\section{Considerações finais}

A impossibilidade da população carcerária de se constituir como ator legítimo na esfera política ficou evidenciada com a frustração da experiência - inédita no Brasil - de formação das Comissões de Solidariedade, pensadas como canais para a defesa de seus direitos e interesses na disputa em torno das políticas para o sistema prisional. O presente texto levantou a hipótese de que o bloqueio dessa tentativa de democratização política no campo prisional acabou por acarretar o represamento de demandas legítimas que não puderam ser legalizadas, legitimadas ou institucionalizadas diante da sociedade. Tais demandas foram, em contrapartida, apropriadas pelo PCC e formaram a base de apoio ideológico que lhe deu sustentação para se estabelecer como instância de representação da população carcerária, tal como se apresenta na atualidade. Instância representativa a um só tempo firmada como produto das políticas prisionais e como ator político extremamente relevante nas discussōes e decisōes relativas ao sistema prisional paulista, mesmo que a atuação violenta desse grupo o situe aquém do horizonte democrático.

O aprofundamento dessa hipótese em novas investigaçōes pode contribuir assim para uma melhor compreensão das inúmeras formas de subjetivi- 
dade coletiva que se organizam nas fronteiras do crime e de sua punição na sociedade brasileira. Sem dúvida, em relação às novas dinâmicas prisionais no país, um conjunto expressivo de trabalhos foi produzido nos últimos anos, inclusive com ênfase na atuação do PCC e seus desdobramentos para além das prisões (cf. Biondi, 2010; Dias, 2011; Feltran, 2008; Godói, 2010; Hirata, 2010; Marques, 2009; Teixeira, 2009, 2012). Uma abordagem como a proposta aqui, ao adotar um escopo temporal mais amplo de análise, que inclui experiências anteriores no espaço prisional como a das Comissóes de Solidariedade, pode descortinar novas possibilidades de compreensão de fenômenos que hoje afetam o imaginário social e mobilizam a ação do Estado.

As possíveis continuidades e descontinuidades da experiência de representação da população carcerária por meio das Comissões de Solidariedade e a posterior constituição do PCC poderão ser analisadas pela pesquisa de fontes variadas, tais como material jornalístico, literatura, documentação e até mesmo entrevistas com atores que direta ou indiretamente estiveram vinculados a esses fenômenos. As denúncias sobre a suposta existência de uma organização de presos denominada Serpentes Negras durante a curta vigência das Comissões de Solidariedade também podem ser objeto de uma reflexão mais detida, pois expressam os conflitos e as tensões presentes no universo prisional, envolvendo os diversos grupos de presos, funcionários, administração e outros setores da sociedade civil e do Estado. Pesquisa já em andamento pretende compreender os efeitos dessas diferentes formas de representação da população carcerária, em termos de seu arcabouço discursivo, de sua base ideológica e das formas pelas quais se considera sua relação com o poder público no cenário político mais amplo.

\section{Referências Bibliográficas}

Adorno, Sérgio \& SAlla, Fernando. (s/d), "As rebeliōes nas prisões do estado de São Paulo". Relatório de Pesquisa para CNPq, São Paulo, mimeo.

Alvarez, Marcos C. (2003), Bacharéis, criminologistas e juristas: saber jurídico e Nova Escola Penal no Brasil. São Paulo, IBCCRIM.

. (2006), "Punição, poder e resistências: a experiência do Groupe d'Information sur les Prisons e a análise crítica da prisão”. In: Alvarez, M. C., Miskolci, R. \& SCAvone, L. (orgs.). O legado de Foucault. São Paulo, Editora da Unesp, vol. 1, pp. 45-60. 
ArtiÈres, Philippe. (2004), "Dizer a atualidade: o trabalho de diagnóstico em Michel Foucault”. In: Gros, F. (org.). Foucault: a coragem da verdade. São Paulo, Parábola, pp. 15-37.

; Quero, Laurent \& ZanCARIni-Fournel, Michelle. (2003), Le Groupe D'Information sur les Prisons: archives de lutes, 1970-1972. Paris, L'Imec.

\& LAsCOumes, Pierre (orgs.). (2004), Gouverner, enfermer: la prison, un modèle indépassable? Paris, Presses de Sciences Po.

BERK, Bernard B. (1966), "Organizational goals and inmate organization”. American Journal of Sociology, 71 (5): 522-534.

BIONDI, Karina. (2010), Junto e misturado: uma etnografia do PCC. São Paulo, Terceiro Nome/Fapesp.

CANDido, Antonio. (1958), "Informação sobre a Sociologia em São Paulo". In: et al. Ensaios paulistas. São Paulo, Anhembi, pp. 510-521.

Castro e Silva, Anderson Moraes de. (2008), Nos braços da lei: o uso da violência negociada no interior das prisões. Rio de Janeiro, e+a.

Chacon, Vamireh. (1977), História das ideias sociológicas no Brasil. São Paulo, Grijalbo/Edusp.

Chantraine, Gilles. (2006a), "Prisons et mutations pénales, nouvelles perspectives d'analyse". Déviance et Société, 30 (3): 267-271.

(2006b), "A prisão pós-disciplinar". Revista Brasileira de Ciências Criminais, 62: 79-106, set./out.

Chauvenet, Antoinette, Orlic, Françoise \& Benguigui, Georges. (1994), Le monde des surveillants de Prison. Paris, PUF.

Christie, Nils. (1999), "Elementos para uma geografia penal”. Revista de Sociologia e Politica, 13: 51-57.

Clemmer, Donald. ([1940] 1958), The prison community. NovaYork, Holt, Rinehart $\&$ Winston.

Coelho, Edmundo Campos. (1987), A oficina do diabo: crise e conflito no sistema penitenciário do Rio de Janeiro. Rio de Janeiro, Iuperj/Espaço e Tempo.

(2005), "Da Falange Vermelha a escadinha: o poder nas prisōes". In: . $A$ oficina do diabo e outros estudos sobre criminalidade. Rio de Janeiro, Record, pp. 337-350.

Combessie, Philippe. (2001), Sociologie de la prison. Paris, La Découverte.

DiAs, Camila Caldeira Nunes. (2009), "Efeitos simbólicos e práticos do Regime Disciplinar Diferenciado (RDD) na dinâmica prisional”. Revista Brasileira de Segurança Pública, 3 (5): 128-144, ago./set.

(2011), Da pulverização ao monopólio da violência: expansão e consolidação da dominação do PCC no sistema carcerário paulista. São Paulo, tese de doutorado em sociologia, Faculdade de Filosofia, Letras e Ciências Humanas, Universidade de São Paulo. 
EGYDiO, Paulo. (1896), Ensaios sobre algumas questôes de direito e de economia política. São Paulo, J. G. de Arruda Leite.

ERIBON, D. (1990), Michel Foucault: uma biografia. São Paulo, Companhia das Letras.

Faugeron, C., Chauvenet, A. \& Combessie, P. (orgs.). (1996), Approches de la prison. Bruxelles, De Boeck Université.

Feltran, Gabriel de Santis. (2008), Fronteiras de tensão: um estudo sobre política e violência nas periferias de São Paulo. Campinas, SP, tese de doutorado, Programa de Pós-Graduação em Ciências Sociais da Unicamp.

FISHER, Rosa Maria. (1989), Poder e cultura em organizaçôes penitenciárias. São Paulo, tese de livre-docência, Faculdade de Economia e Administração da Universidade de São Paulo.

Foucault, Michel. (1987), Vigiar e punir: nascimento da prisão. Petrópolis, Vozes. . (2006), Estratégia, poder-saber: ditos e escritos IV. Rio de Janeiro, Forense Universitária.

GARLAND, David. (2001), The culture of control: crime and social order in contemporary society. Chicago, University of Chicago Press.

GODÓI, Rafael. (2010), Ao redor e através da prisão: cartografias do dispositivo carcerário contemporâneo. São Paulo, dissertação de mestrado em sociologia, Faculdade de Filosofia, Letras e Ciências Humanas da Universidade de São Paulo.

GÓEs, Eda Maria. (1991), A recusa das grades: rebelióes nos presídios paulistas, 19821986. São Paulo, dissertação de mestrado em história, Faculdade de Ciências e Letras de Assis da Unesp.

Goffman, Ervin. ([1961] 1974), Manicômios, prisões e conventos. São Paulo, Perspectiva.

HAYNER, Norman S. \& ASH, Ellis. (1939), “The prisoner community as a social group”. American Sociological Review, 4 (3): 362-369.

HirATA, Daniel Veloso. (2010), Sobreviver na adversidade: entre o mercado e a vida. São Paulo, tese de doutorado em sociologia, Faculdade de Filosofia, Letras e Ciências Humanas da Universidade de São Paulo.

JozINO, Josmar. (2005), Cobras e lagartos - a vida intima e perversa nas prisóes brasileiras: quem manda e quem obedece no partido do crime. Rio de Janeiro, Objetiva.

LEAL, Aurelino. (1902), Estudos de sociologia e psychologia criminal. Bahia, Reis \& Comp. Editores.

Lima, William da Silva. (1991), Quatrocentos contra um: uma história do Comando Vermelho. Petrópolis, Vozes/Iser.

MARQues, Adalton. (2009), Crime, proceder, convivio-seguro: um experimento antropológico a partir de relaçôes entre ladrôes. São Paulo, dissertação de mestrado em antropologia social, Faculdade de Filosofia, Letras e Ciências Humanas da Universidade de São Paulo. 
MCCleERY, Richard H. (1975), "Mudança de política na administração de presídios". In: ETZIONI, Amitai. Organizaçôes complexas: estudo das organizaçôes em face dos problemas sociais. São Paulo, Atlas, pp. 191-198.

MiCELI, Sergio (org.). (1989), História das ciências sociais no Brasil. São Paulo, Vértice, vol. 1.

Neves, Delma P. (1993), "Políticas públicas: intenções previstas e desdobramentos inesperados”. In: DinIZ, E., LOPES. J. S. L. \& PRANDI, R. (orgs.). Ciências sociais hoje. São Paulo, Hucitec/Anpocs, pp. 45-85.

PAIXÃO, Antônio L. (1987), "Falanges vermelhas, serpentes negras e a ordem prisional". In: Recuperar ou punir? Como o Estado trata o criminoso. São Paulo, Cortez, pp. 73-88.

Pinheiro, P. S. \& Braun, E. (1986), Democracia versus violência. Rio de Janeiro, Paz e Terra.

RAmalHo, José Ricardo. (1979), Mundo do crime: a ordem pelo avesso. Rio de Janeiro, Graal.

Rodrigues, Nina. ([1894] 1957), As raças humanas e a responsabilidade penal no Brazil. Rio de Janeiro, Guanabara.

Rostaing, C. (1997), La relation carcérale: indentités et rapports sociaux dans les prisons de femmes. Paris, PUF.

Rusche, G. \& KirchHeimer, O. (1939), Punishment and social structure. New York, Columbia University Press.

SALlA, Fernando. (2006), "As rebeliōes nas prisōes: novos significados a partir da experiência brasileira”. Sociologias, 16: 274-307.

. (2007), "De Montoro a Lembo: as políticas penitenciárias de São Paulo”. Revista Brasileira de Segurança Pública, 1 (1): 72-90.

SHRAG, Clarence. (1954), "Leadership among prison inmates". American Sociological Review, 19 (1): 37-42.

SouZA, Fátima. (2007), PCC: a facção. Rio de Janeiro, Record.

SpARKS, J. R. \& BOTtoms, A. E. (1995), "Legitimacy and order in prisons". The British Journal of Sociology, 46 (1): 45-62.

SYKES, Gresham M. (1969), Crime e sociedade. Rio de Janeiro, Bloch.

([1958] 1974), The society of captives: a study of a maximum security prison. New Jersey, Princeton University Press.

TeIXeIra, Alessandra. (2009), Prisóes da exceção: política penal e penitenciária no Brasil contemporâneo. Curitiba, Juruá.

(2012), Construir a delinquência, articular a criminalidade: um estudo sobre a gestão dos ilegalismos na cidade de São Paulo. São Paulo, tese de doutorado em sociologia, Faculdade de Filosofia, Letras e Ciências Humanas da Universidade de São Paulo. 
TitTLE, Charles R. (1969), "Inmate organization: sex differentiation and the influence of criminal subcultures". American Sociological Review, 34 (4): 492-505.

VASSeur, Véronique. (2000), Médicin-chef à la prison de La Santé. Paris, Le Cherche Midi.

WACQUANT, L. (2001), As prisões da miséria. Rio de Janeiro, Jorge Zahar.

WeInBERG, S. Kirson. (1942), “Aspects of the prison's social structure”. The American Journal of Sociology, 47 (5): 717-726.

\section{Resumo}

Das Comissões de Solidariedade ao Primeiro Comando da Capital em São Paulo

$\mathrm{O}$ artigo analisa duas experiências de ação e de representação dos presos no sistema penitenciário paulista: as Comissões de Solidariedade e o Primeiro Comando da Capital (PCC). A hipótese sustentada é de que a obstrução à existência de mecanismos de comunicação e representação de presos, legitimados pelas autoridades, favoreceu a formação de um grupo que se impôs à massa carcerária pela violência mas que, ao mesmo tempo, buscou fundamentar sua "legitimidade" nas denúncias das deficiências do sistema prisional e também nos códigos de conduta formulados a partir do mundo do crime. A reflexão recupera a literatura nacional e internacional sobre a presença de grupos nas prisões, bem como material documental e da imprensa.

Palavras-chave: Punição; Prisão; Direitos humanos; Democratização; Dinâmica prisional; PCC.

\section{Abstract}

From Solidarity Commissions to the Primeiro Comando da Capital in São Paulo

Texto recebido em 10/1/2013 e aprovado em 24/1/2013.

Marcos César Alvarez é professor de sociologia na Universidade de São Paulo e pesquisador sênior do Núcleo de Estudos da Violência. E-mail: <mcalvarez@usp.br>.

Fernando Salla é pesquisador sênior do Núcleo de Estudos da Violência da Universidade de São Paulo. E-mail: <fersalla@usp.br>.

Camila Nunes Dias é doutora em sociologia, professora da UFABC e pesquisadora do Núcleo de Estudos da Violência da Universidade de São Paulo. E-mail: <camila. dias00@gmail.com>.
This article analyzes two instances of prisoner action and representation of prisoners in the São Paulo penitentiary system: the Solidarity Commissions and the Primeiro Comando da Capital (PCC). Our hypothesis is that obstruction of the mechanisms of inmate communication and representation legitimized by the authorities stimulated the formation of prisoner groups, which imposed themselves on the prison population through violence, while simultaneously seeking to 'legitimize' themselves through denunciations of the deficiencies in the prison system and through the codes of conduct formulated in the crime world. The analysis draws from the national and international literatures on prisoner groups, as well as material from official documents and the press. Keywords: Punishment; Prison; Human rights; Democratization; Prison dynamics; PCC. 